\title{
Different thermal stimuli initiate hatching of Daphnia diapausing eggs originating from lakes and temporary waters
}

\author{
Jacek Radzikowski $^{1} \cdot$ Katarzyna Krupińska $^{1} \cdot$ Mirosław Ślusarczyk $^{1}$
}

Received: 10 August 2016/Accepted: 30 March 2017/Published online: 10 May 2017

(c) The Author(s) 2017. This article is an open access publication

\begin{abstract}
The simultaneous hatching of Daphnia resting eggs from a number of different lakes and ponds using one set of hatching cues can be difficult to achieve as environmental conditions differ considerably between water bodies. Therefore, optimal hatching conditions for ephippial eggs originating from shallow temporary waters may differ from those found in large lakes. The aim of our study was to compare the optimal thermal conditions for hatching ephippial eggs of Daphnia found in permanent lakes and those from shallow temporary ponds. We used ephippial eggs of Daphnia from the longispina species complex originating from two temporary city ponds and two deep lakes in Poland. The ephippia were protected against overheating at all stages of the field and laboratory work to prevent activation or killing of the eggs. After a refractory period (imposed storage in cool and dark conditions), ephippia were incubated at six different temperatures $(6,9$, $12,15,18$ and $21{ }^{\circ} \mathrm{C}$ ) under a 16:8 L:D light regime. Our results indicate that hatching of resting eggs of Daphnia that inhabit lakes or ponds may require different thermal conditions. The hatching success of ephippial eggs originating from temporary waters was relatively high (30-56\%) at all tested incubation temperatures, while for the ephippial eggs from the deep lakes it was lower $(7-37 \%)$ and inversely related to water temperature. The divergent hatching responses of the ephippial eggs originating from temporary pools and lakes may reflect the
\end{abstract}

Handling Editor: Masaki Sakamoto.

Jacek Radzikowski

jacekasdf@wp.pl

1 Department of Hydrobiology, Faculty of Biology, Biological and Chemical Research Centre, University of Warsaw,

Żwirki i Wigury 101, 02-089 Warsaw, Poland typical thermal conditions during hatching in their native habitats. While in the deep lakes of the temperate zone Daphnia hatching typically occurs during the low water temperatures of early spring, in shallow ponds Daphnia hatching may occur throughout the year at varying water temperatures, from a few to over a dozen degrees Celsius.

Keywords Daphnia · Diapause · Ephippia · Hatching · Zooplankton

\section{Introduction}

The formation of resting stages is a common strategy for living creatures to survive periods of adverse environmental conditions (Dahms 1995; Ślusarczyk 1998). Production of diapausing eggs is frequent in planktonic cladocerans of the genus Daphnia, commonly used as model animals in ecological and toxicological research (Lampert 2011). Different Daphnia species inhabit almost all types of freshwater bodies-from environmentally unstable and unpredictable bodies such as small puddles (Hotovy and Petrusek 2007) to relatively stable deep lakes (Caceres 1998) and brackish waters (Viitasalo and Katajisto 1994).

Daphnia females switch from the production of subitaneous to diapausing eggs as environmental conditions deteriorate. These dormant eggs, covered by chitinous envelopes called ephippia (Schultz 1977), are often the only means for a Daphnia population to survive if a lack of resources (e.g., food or oxygen), drying or freezing of the water body kills all active individuals. Ephippial eggs are not only produced by Daphnia in unstable or temporary habitats, but also in less variable and predictably changing deep lakes, where the risk of whole active populations 
disappearing is relatively low. In the latter case the production of resting stages could be a means to survive harsh winters (e.g., food scarcity, oxygen depletion) or ice cover of higher latitude or mountain lakes (Jones and Gilbert 2016), an element of a bet-hedging survival strategy (Seger and Brockmann 1987; Brendonck and De Meester 2003), or the ephippia can be predestined for spatial dispersal (Pietrzak and Ślusarczyk 2006). Regardless of the ultimate reason for ephippia production, they can be found in most lakes and small water bodies at most latitudes, including the temperate zone.

Worldwide prevalence and easy access to ephippia make them a convenient source of Daphnia clonal lines for experimental plankton studies (Weider et al. 1997; Lampert 2011). Hatching of Daphnia from ephippial eggs can offer an almost constant supply of new clonal lines since, unlike subitaneous eggs, most of them are formed sexually (Lampert 2011). Daphnia resting eggs are long-lived (Radzikowski 2013) and can thus be hatched after a long storage period. Hence, access to new clonal lines may be possible long after field sampling. Furthermore, Daphnia can be hatched from ephippia of different ages (derived from different layers of lake sediment), which is used in socalled "resurrection ecology" (Kerfoot and Weider 2004).

Ephippial eggs originating from the temperate zone are mainly activated by a combination of two stimuli: light/ photoperiod and temperature regimes (e.g., Stross 1966; Vandekerkhove et al. 2005). Unfortunately, hatching of Daphnia from resting eggs is not always a simple task as "standard light and temperature conditions" offering high hatching success may not exist. In general, high hatching rates from ephippial eggs have been mainly observed in $D$. magna - a large Ctenodaphnia that inhabits mostly temporary waters (but is also found in some shallow lakes) probably the most extensively studied species of the genus Daphnia. Doma (1978) demonstrated a hatching success of 40-60\% for preconditioned (air-dried) D. magna ephippia derived from laboratory cultures. High $D$. magna hatching rates (exceeding 50\%) have also been reported by other researchers (Schwartz and Hebert 1987; De Meester and De Jager 1993; Moreira dos Santos and Persoone 1998), but high hatching success has often only been observed for some of the tested clones/places of ephippia origin. The hatching success of D. magna ephippial eggs may vary (in one study or between different studies) because of different thermal conditions (Schwartz and Hebert 1987), the age of ephippia (De Meester and De Jager 1993) and different storage periods and storage conditions prior to incubation (De Meester and De Jager 1993; Moreira dos Santos and Persoone, 1998).

Furthermore, hatching of Daphnia ephippial eggs from the pulex/pulicaria species complex has also been extensively studied. For these species, the place of Daphnial ephippia origin, incubation temperature, light conditions and length of storage/storage conditions strongly affect hatching success (e.g., Pancella and Stross 1963; Stross 1966; Pfrender and Deng 1998). The stimuli required for ephippial egg hatching varied not only for eggs belonging to a species inhabiting different environments, but also for ephippia derived from different conspecific clones originating from the same sampling sites (Schwartz and Hebert 1987). As a result, mean hatching rates varied between ephippial eggs derived from different clonal lines of a species incubated under the same conditions, even when the tested clonal lines originated from the same (or similar) environments.

Hatching of ephippial eggs of Daphnia longispina species complex has shown even more ambiguous results. Carvalho and Wolf (1989) reported a hatching success of up to $14.4 \%$ when incubating ephippia collected from the top $8 \mathrm{~cm}$ of sediments from two deep lakes in Germany under constant light at $12{ }^{\circ} \mathrm{C}$. Higher $\left(20^{\circ} \mathrm{C}\right)$ and lower $\left(6{ }^{\circ} \mathrm{C}\right)$ temperatures resulted in lower hatching rates. On the other hand, Weider et al. (1997) hatched more than $75 \%$ of the resting eggs of Daphnia longispina species complex found in samples of the top $10.5 \mathrm{~cm}$ of sediment from the deep Lake Constance using almost identical hatching conditions. Furthermore, resting eggs of Daphnia longispina complex from different regions of the brackish Baltic Sea, incubated at one temperature, showed different hatching successes (Viitasalo and Katajisto 1994).

All the aforementioned studies indicate that hatching of Daphnia ephippial eggs can be difficult and unpredictable. We hypothesize that different hatching stimuli may be needed for activation of ephippial eggs of closely related Daphnia originating from different types of water bodies. Schwartz and Hebert (1987) found differences in the thermal requirements for hatching $D$. pulex ephippial eggs originating from different regions, but this species is typically found in shallow and highly variable habitats.

The aim of our study was to compare optimal thermal conditions for the hatching of Daphnia ephippial eggs originating from two contrasting types of water bodies: deep permanent lakes vs. shallow temporary ponds. As the thermal conditions during Daphnia hatching periods in these two types of water bodies vary a lot (from a few degrees Celsius in lakes to $\sim 15{ }^{\circ} \mathrm{C}$ in ponds in spring; Kozłowska 2012; Daphnia also hatch sporadically in Warsaw city ponds during the warmer parts of year; pers. obs.), we suspected that the optimum thermal hatching conditions for Daphnia ephippial eggs originating from lakes and ponds may differ. We chose D. longispina complex cladocerans as the model animals as they dominate in lakes and many temporary ponds in Central-Eastern Europe. As we are not aware of any studies conducted on the hatching of D. longispina complex ephippia from 
freshwaters in this region, our research is the first to propose optimal thermal conditions for their successful hatching.

\section{Methods}

\section{Lake ephippia sampling and storage}

Sediment samples containing ephippia were collected from two eutrophic lakes, Orzysz $\left(53^{\circ} 50^{\prime} 21^{\prime \prime} \mathrm{N}, 22^{\circ} 03^{\prime} 23^{\prime \prime} \mathrm{E}\right)$ and Białoławki $\left(53^{\circ} 44^{\prime} 13^{\prime \prime} \mathrm{N}, 21^{\circ} 49^{\prime} 40^{\prime \prime} \mathrm{E}\right)$, located in northeast Poland, in October 2013 (time of the autumnal peak of ephippia formation). Both lakes are relatively large (1011 and 211 ha, respectively) and deep (maximum depth 36.0 and $36.1 \mathrm{~m}$, respectively; Jańczak 1999). Lake sediment was collected during daytime hours from the deepest points of the lakes with a modified Ekman sampler that collected only the top $2-3 \mathrm{~cm}$ of sediment (i.e., relatively young sediment and ephippia). Collected samples were immediately transferred into black plastic bags and placed in a portable refrigerator $\left(4^{\circ} \mathrm{C}\right)$ to prevent any substantial changes in temperature. They were subsequently transported to a laboratory in Warsaw for storage (in a dark cold room at $4-5^{\circ} \mathrm{C}$ ) for about 3 months until the time when the hatching test was performed.

\section{Temporary pond ephippia sampling and storage}

As the temporary waters we chose two city ponds located in Warsaw: one in Pole Mokotowskie park (abbreviated hereinafter as Mokotowskie pond; $52^{\circ} 12^{\prime} 43^{\prime \prime} \mathrm{N}$ $21^{\circ} 00^{\prime} 04^{\prime \prime} \mathrm{E}$ ) and the second in Bródnowski Park (abbreviated Bródno pond; $52^{\circ} 17^{\prime} 30^{\prime \prime} \mathrm{N} 21^{\circ} 02^{\prime} 15^{\prime \prime} \mathrm{E}$ ). Both ponds are temporary (drained in late autumn and refilled with water in spring; both are also occasionally drained in summer) and have concrete floors. Mokotowskie pond is half the size of Bródno pond $(\sim 0.29$ vs. $\sim 0.57$ ha, respectively). Both ponds are very shallow, and in both the water level varies throughout the growing season (from $\sim 0.2$ to $\sim 1 \mathrm{~m}$ ).

Ephippia from the two city ponds were collected differently from those from the lakes. City ponds with solid concrete bottoms are devoid of thick sediment layers, which are removed regularly in late autumn when the water is drained. Furthermore, in the growing season green algal mats cover the bottoms, making it impossible to collect ephippia with the same approach we used in the lakes. Thus, in both ponds we collected ephippial and nonephipial Daphnia with a plankton landing net. The sampling was performed in September/October 2013 during the autumnal peak of ephippia formation. The largest females (mostly Daphnia magna) were sifted out and returned to their native ponds, and only the smaller $D$. longispina complex animals were transported to the laboratory. The animals were subsequently transferred to 120-1 black plastic barrels filled with filtered $(1 \mu \mathrm{m})$, aerated lake water. The barrels were kept at $16{ }^{\circ} \mathrm{C}$ and illuminated from the top with a fluorescent light set at a 12:12 L:D light regime. Additionally, we used constant lighting by a safe fluorescent UV tanning lamp (40 W Phillips Cleo) to "discourage" Daphnia females from depositing ephippia on the water surface.

After 2 weeks all ephippia that had been deposited in the water column (thus most likely conceived in the ponds) were collected together with the bottom sediment and water and transferred to darkened 1-1 jars. The jars were kept in a cold room $\left(4-5{ }^{\circ} \mathrm{C}\right)$ for a minimum of 3 months until the hatching test began.

\section{Sediment processing}

After storage in the cold room, the sediment with ephippia was rinsed through a $150-\mu \mathrm{m}$ sieve with cold tap water. The sieved lake sediment was subsequently flooded with cooled $\left(4^{\circ} \mathrm{C}\right)$ 1:1 sucrose:filtered tap water solution and centrifuged for $10 \mathrm{~min}$ at $1000 \mathrm{rpm}$ (modified sugar flotation method; Onbé 1978). The supernatant was rinsed again with cold tap water through a $150-\mu \mathrm{m}$ sieve, and the isolated material was placed, using a glass pipette, in cooled $\left(4{ }^{\circ} \mathrm{C}\right)$ filtered $(0.2 \mu \mathrm{m})$ lake water in darkness for the time of ephippia isolation prior to the experiment (maximum a few hours). The sediment with pond Daphnia ephippia was not sugar-floated but directly placed in filtered cooled water after the first sieving.

\section{Experimental design}

All Daphnia ephippia from the longispina species complex were isolated from the sieved samples in cold water under a stereoscopic microscope equipped with a cold LED light. We placed small samples of the sieved material under the microscope and flooded them with cold filtered water to minimize ephippia exposure to temperatures higher than a few degrees Celsius. Before setting the experiment, 20 ephippia were haphazardly chosen from each of the water bodies and opened with fine dissecting needles to assess the quantity and quality of ephippial eggs. Most ephippia contained two apparently viable eggs. Subsequently, samples of 12 randomly chosen ephippia (which corresponded to $\sim 20$ eggs) were randomly assigned to one of six temperature treatments $\left(6,9,12,15,18\right.$ and $\left.21{ }^{\circ} \mathrm{C} \pm 0.2{ }^{\circ} \mathrm{C}\right)$. There were ten replicates for each treatment. In each replicate 12 ephippia were placed together into a single well of a multiwell culture plate. The wells were filled with $3 \mathrm{ml}$ of cold, filtered $(0.2 \mu \mathrm{m})$ lake water beforehand. Each 
multiwell plate corresponded to one water body/temperature treatment (with 12 ephippia from one water body in each of the 10 wells/replicates).

On the first day of the experiment all the multiwell plates with ephippia were transferred to 25-1 water baths (used as a thermal buffer) placed in six climate chambers. Each chamber was assigned to one thermal treatment. During the experiment, each climate chamber contained a water bath with four multiwell plates-one plate per each of the four water bodies tested. The incubated ephippia were illuminated with fluorescent light of $56 \mu \mathrm{mol} \mathrm{m}{ }^{-2}$ $\mathrm{s}^{-1}$ intensity and 16:8 L:D light regime. The chosen photoperiod had been successfully used to hatch Cladocera from a similar climate (e.g., Vandekerkhove et al. 2005).

Every 2 days all the wells were checked for newly hatched Daphnia under a stereoscopic microscope equipped with a cold LED light source. To avoid changes of temperature during the checking process the multiwell plates were not placed directly onto the microscope table but instead transferred to Petri dishes filled with water at a temperature corresponding to the thermal treatment. All neonates were counted and removed from the wells. Water removed with the animals was replaced with filtered lake water of the corresponding temperature. The experiment lasted 7 weeks.

\section{Egg mortality}

After 7 weeks of incubation ephippia from the first five replicates of each treatment were opened with fine dissecting needles to assess the number and viability of the eggs that did not hatch. The viability was assessed visually-eggs with an unusual shape, structure or color were classified as dead.

\section{Statistical analysis}

The quantity of hatched individuals was compared by an analysis of variance using Analytical Software Statistix version 9. The effect of various incubation temperatures on the quantity of hatching neonates was tested separately for each water body (before performing the ANOVA tests the homogeneity of variance assumption was tested with Levene's test: in all cases the null hypothesis of equal variances was not rejected; $p>0.05$ ). Homogeneous groups of treatments were determined with an LSD post hoc test.

The effect of water body type and temperature on egg mortality (number of apparently dead eggs found in ephippia after incubation) was tested with an analysis of deviance and generalized linear models with a defined log$\log$ function and binomial error distribution in Statsoft Statistica package version 12.5 .

\section{Results}

\section{Hatching of Daphnia at various temperatures}

In general, higher hatching rates were observed for ephippial eggs originating from temporary ponds (Fig. 1a, c) than from lakes (Fig. 1b, d). The mean hatching proportion varied from $31 \%( \pm 2.7 \% \mathrm{SE})$ at the lowest temperature to $56 \%( \pm 5.2 \% \mathrm{SE})$ at the highest in ephippial eggs from Bródno, and from $43 \%( \pm 6.3 \% \mathrm{SE})$ in the lowest temperature to $30 \%$ ( $\pm 5.4 \% \mathrm{SE})$ in the highest in ephippial eggs from Mokotowskie. No differences between hatching rates at different temperatures were found in ephippia from Mokotowskie (ANOVA, $F=0.73$,
Fig. 1 Mean $( \pm 1 \mathrm{SE})$ percentage of Daphnia neonates hatched from: a Bródno pond, b Lake Orzysz, c Mokotowskie pond and d Lake Białoławki ephippia. Capital letters above the bars indicate homogeneous groups of treatments (ANOVA + LSD post hoc test; a $p=0.0013$, b $p<0.0005$, c $p=0.6054, \mathbf{d} p=0.0149$ )
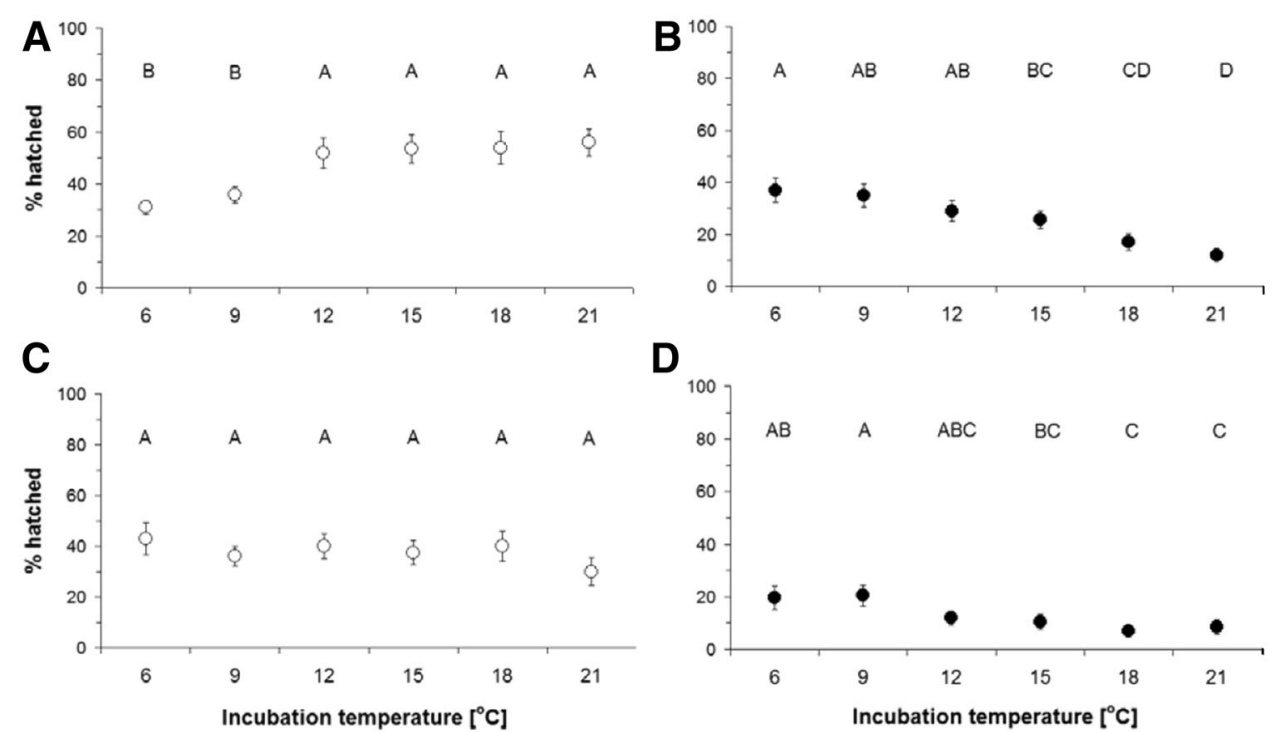
$p=0.6054)$ while significantly lower hatching rates were found at the lowest two tested temperatures $\left(6\right.$ and $\left.9{ }^{\circ} \mathrm{C}\right)$ in ephippia from Bródno (ANOVA, $F=4.65, p=0.0013$; homogeneous groups detected with LSD post hoc test).

Resting eggs from the two lakes hatched at lower rates: from $12 \%( \pm 2.1 \% \mathrm{SE})$ to $37 \%( \pm 4.7 \% \mathrm{SE})$ at various temperatures for ephippial eggs from Orzysz Lake and from $7 \%( \pm 2.0 \% \mathrm{SE})$ to $20.5 \% \quad( \pm 3.9 \% \mathrm{SE})$ for Białoławki (Fig. 1b, d). Although hatching success was generally lower for ephippial eggs from Białoławki Lake, the trends in hatching rates along the tested temperatures appeared similar for ephippial eggs from both lakes, with the highest rates at the lowest temperatures and the lowest rates at the highest temperatures (ANOVA; $F=3.13$, $p=0.0149$ for Białoławki; $F=6.99, p<0.0005$ for Orzysz; homogeneous groups detected with LSD post hoc test).

\section{Hatching time}

Daphnia hatching was checked every 2 days, starting from the 3 rd day of incubation. The first hatchlings were observed on the 5 th day (at $21{ }^{\circ} \mathrm{C}$ ). The timing of hatching patterns was similar within both the pond and lake groups, so on the graphs the results were pooled to present the general trends more clearly (Figs. 2, 3). The hatching peaks were earlier at higher temperatures: 21,18 and $15{ }^{\circ} \mathrm{C}$ for both lake and pond material. Hatching almost completely ceased after 2 weeks of incubation at higher temperatures. In contrast, hatching at the three lowest temperatures started and ceased later on (Figs. 2, 3). Notably, numbers of hatchlings from lake ephippia were highest at the three lowest temperatures tested (Fig. 1b, d), so the time to obtain a relatively high hatching success was generally longer for the lake material (Fig. 3) than pond material (Fig. 2).
Fig. 2 Cumulative hatching rates from temporary pond ephippia over time at various temperatures. Pooled results for Bródno and Mokotowskie material
Fig. 3 Cumulative hatching rates from lake ephippia over time at various temperatures. Pooled results for Orzysz and Białoławki material
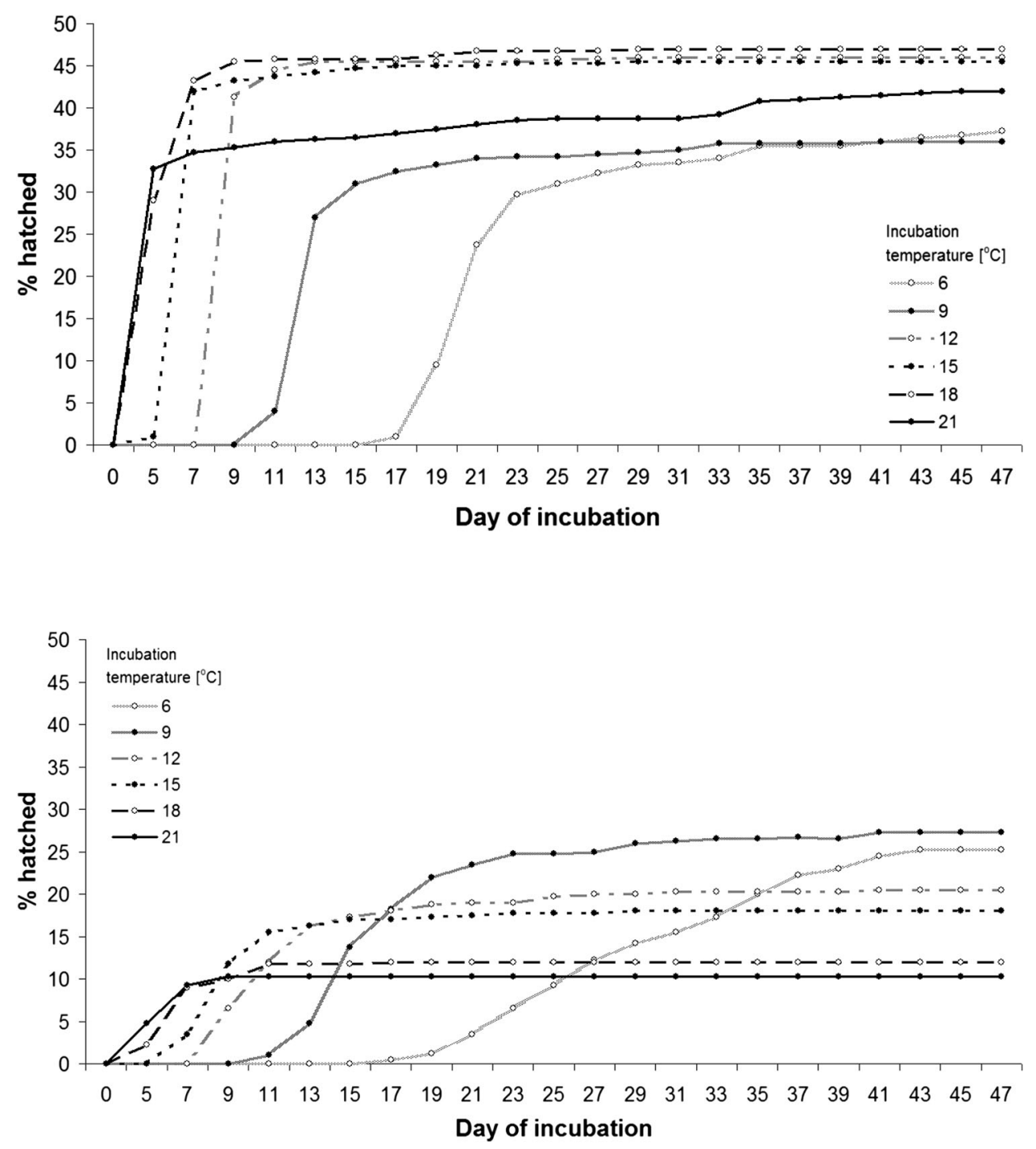


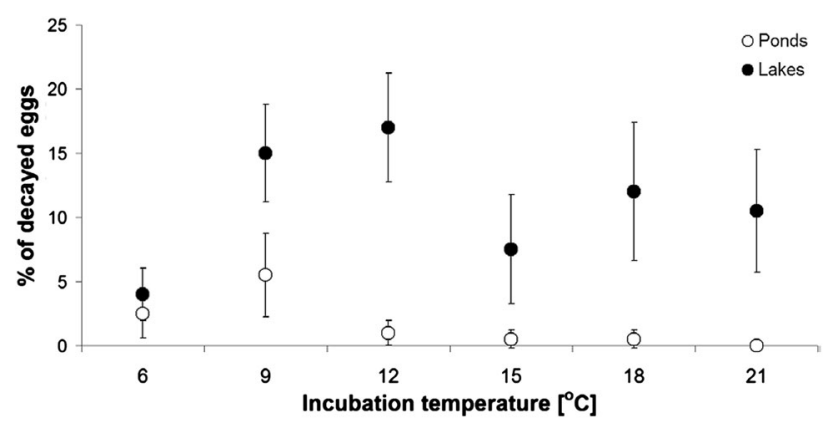

Fig. 4 Mean ( \pm 1 SE) proportion of nonviable eggs of Daphnia, compared to their initial number, at the end of the incubation period at each temperature. Pooled results for lake and pond material (GLZ; ponds vs. lakes: $p=0.5409$, temp.: $p=0.0026$, pond vs. lakes *temp.: $p=0.0006$ )

\section{Egg mortality}

We pooled the results for egg mortality (those that did not hatch over the course of the study) for the two ponds and two lakes separately because the quantity of eggs classified as nonviable was similar within each group. We found very low numbers of apparently dead eggs in the pond samples $(1.7 \pm 0.5 \%$; mean \pm 1 SE; Fig. 4$)$ and higher numbers in the lake samples $(11.0 \pm 1.3 \%$; mean \pm 1 SE; Fig. 4). Nevertheless, these results were not significantly different (GLZ, Wald Stat. 0.37, $p=0.5409$ ). On the other hand, the proportions of nonviable eggs differed significantly between the various temperatures (GLZ, Wald Stat. 9.10, $p=0.0026$ ). Furthermore, the interaction between incubation temperature and water body type had a significant effect on the proportion of nonviable eggs (GLZ, Wald Stat. $11.89, p=0.0006)$. Interestingly, for pond material the mean number of decayed eggs did not exceed $5 \%$ in all but one temperature treatment $\left(9^{\circ} \mathrm{C}\right)$. In contrast, for lake material it was higher than $5 \%$ in all but one $\left(6^{\circ} \mathrm{C}\right)$ treatment.

\section{Discussion}

The hatching of Daphnia resting eggs has been described by many researchers, starting with the early works of Sars $(1885,1888)$ and the later efforts of Wood and Banta (1933, 1937). However, studies to determine the optimal hatching conditions for various species of Daphnia are scarce and focus mainly on D. pulex/pulicaria complex and Ctenodaphnia (e.g., Schwartz and Hebert 1987). The most comprehensive study on the hatching conditions of different species of Cladocera typical for temperate climates in Europe was conducted by Vandekerkhove et al. (2005). They investigated the hatching of animals from sediment from 95 shallow lakes in Western Europe under various light and thermal conditions. However, data are still missing on the ultimate hatching conditions for resting eggs of Daphnia of the longispina species complex, one of the most common cladocerans in lakes and temporary pools in Central Europe. This study is, to our knowledge, the first to compare optimal thermal conditions for the hatching of resting eggs of closely related cladocerans (Daphnia from the longispina species complex) inhabiting strikingly different types of freshwater lentic habitats.

\section{Hatching rates at various temperatures}

Our main results (Fig. 1a-d) support previous findings that indicate differences in the hatching successes of closely related Daphnia from eggs originating from different water bodies (e.g., Schwartz and Hebert 1987; Carvalho and Wolf 1989). Hatching from ephippia originating from deep lakes (Fig. 1b, d) was lower than those from ponds (Fig. 1a, c). Moreover, hatching success of resting eggs from the lakes was highest at the three lowest tested temperatures (Fig. 1b, d), while those from the ponds hatched relatively well at all tested temperatures (Fig. 1a, c). These results support our hypothesis that optimal hatching conditions may differ between the two types of habitat.

In temperate climates spring temperatures near the bottom of deep lakes, where ephippia accumulate in the highest quantities, usually do not exceed $6-8{ }^{\circ} \mathrm{C}$ (e.g., Surga 2007); indeed, in our experiment the highest hatching rates from the lake material were observed at similar temperatures $\left(6\right.$ and $\left.9{ }^{\circ} \mathrm{C}\right)$. On the other hand, temperatures in Warsaw's shallow pools in early spring are usually higher than at the bottom of deep lakes (e.g., in Mokotowskie pond the temperature is usually above $10{ }^{\circ} \mathrm{C}$; Mikulski pers. inf.) and vary depending on weather conditions. In such habitats Daphnia also occasionally hatch from ephippial eggs in the late spring/early summer when the water temperature is much higher (pers. obs.). In our experiment relatively high hatching rates were observed in all temperature treatments for pond material, which may correspond to the unpredictable thermal conditions in the native water bodies.

Thus, our results confirm that there are no "universal thermal conditions" stimulating hatching of ephippial eggs of Daphnia from all temperate climate water bodies. Nevertheless, our results may indicate some general trends. It seems that higher rates of hatching of ephippial eggs originating from the deep lakes may be stimulated by relatively low temperatures (up to $12{ }^{\circ} \mathrm{C}$, which corresponds to spring conditions near the lake bottom). The diapausing eggs of Daphnia from the temporary city ponds hatch well at a broader range of thermal conditions (which corresponds to the various thermal conditions that occur in small water bodies at Daphnia hatching time). 


\section{Hatching time}

The analysis of Daphnia hatching time (Figs. 2, 3) revealed that hatching started and ended earlier at the higher than at the lower temperatures tested. This is probably caused by a lower metabolic rate of activated eggs in colder water (e.g., Childress et al. 1990). A long period of incubation is required to observe relatively high hatching rates from lake ephippia (Fig. 3), as they hatch in high numbers only at low temperatures. A temperature of $12{ }^{\circ} \mathrm{C}$ seems most effective to resurrect high quantities of lake Daphnia from dormant eggs in a relatively short period of time, as in this treatment most of the animals hatched before the end of the third week of incubation. A similar temperature $\left(10-12^{\circ} \mathrm{C}\right)$ was used with great success to hatch resting eggs of lake Daphnia by Weider et al. (1997). Our study suggests such temperatures can also be effective for hatching ephippial eggs of $D$. longispina from temporary waters (Figs. 1a, c, 2) and that they can be applied in cases where similar thermal conditions are required in comparative studies.

\section{Egg mortality}

While the proportion of nonviable eggs was not significantly different between propagules originating from the two water body types, we observed slightly more eggs classified as nonviable in the lake material compared to the pond material. This can be explained in two ways. First, the lake resting eggs may be more vulnerable to some external factors not controlled in our study (e.g., microbial activity). Second, it could be related to the different method of ephippia collection: although we used an Ekman sampler that collected only the very top layer of sediment, some ephippia may have been older than others and thus nonviable as the viability of zooplankton resting stages decreases with age (e.g., Hairston et al. 1995; Weider et al. 1997; Cousyn and De Meester, 1998). Ephippia from the ponds all came from the most recent season. Therefore, the fact that part of the lake material was older could have caused higher lake egg mortality. The relatively low proportion of apparently dead eggs in the lake ephippia incubated at $6{ }^{\circ} \mathrm{C}$ (Fig. 4) may have been caused by the fact that the process of decay is slower at lower temperatures; thus, perhaps some dead eggs still remained "healthy" in appearance.

\section{Experimental and sampling procedure}

Ephippia originating from lakes and ponds, as noted above, were sampled and processed using different methods as we were unable to collect sediment from the temporary ponds due to the algal mats that covered their bottoms. On the other hand, the collection of high quantities of ephippial females in the lakes would have been difficult because of much lower Daphnia densities in such habitats compared to city ponds. The sampled ephippial and nonephippial females from city ponds were placed in barrels with a water temperature similar to that observed in the field and placed under a similar photoregime. As the freshly shed ephippia collected from the barrels originated from a single season, we also aimed to collect ephippia of a comparable age from the lakes. To achieve this, we used an Ekman sampler modified to collect only the top 2-3 cm layer of sediment, containing a high proportion of freshly shed ephippia (the sampling was performed during the peak of ephippia production in autumn). Furthermore, to minimize the side effects of the different ages of parts of the material, we stored all the ephippia in a dark cold room for at least 3 months to let freshly formed resting eggs complete the refractory period and be ready to terminate diapause. To minimize differences in storage conditions, in all cases the ephippia were stored in dark natural sediment (which for pond samples was created over the course of the 2-weeklong period in barrels).

There was also a difference in the processing of material from lakes and ponds as only the lake Daphnia ephippia were subjected to sugar flotation (as there was no need for floating of those from the ponds). This procedure, as stated by Lukić et al. (2016), should have neither a negative nor positive effect on Daphnia hatching; thus, this difference in experimental procedures is unlikely to have affected the hatching rates in our research.

\section{Conclusion}

In conclusion, our results refuted the existence of "universal thermal conditions" for the successful hatching of ephippial eggs of Daphnia from the longispina complex species. While the ephippial eggs of Daphnia from ponds may hatch at a relatively wide range of thermal conditions, those from deep lakes hatch better at low temperatures. This correlation, in the face of climate change predictions, may affect lake Daphnia hatching phenology. The higher the spring temperature will be, the faster the deep lake waters will reach thermal conditions allowing Daphnia hatching. This, in turn, will likely prolong Daphnia occurrence in the water column in lakes, which may affect the ecological dynamics of phytoplankton, zooplankton and fish communities.

Acknowledgements We thank Tomasz Karasek for his help during lake sediment sampling and the anonymous reviewers for making many insightful comments that improved the manuscript. This study was supported by the Polish National Science Centre (Grant 2012/05/ 
B/NZ8/01232). The experiments comply with the current laws in Poland.

Open Access This article is distributed under the terms of the Creative Commons Attribution 4.0 International License (http://crea tivecommons.org/licenses/by/4.0/), which permits unrestricted use, distribution, and reproduction in any medium, provided you give appropriate credit to the original author(s) and the source, provide a link to the Creative Commons license, and indicate if changes were made.

\section{References}

Brendonck L, De Meester L (2003) Egg banks in freshwater zooplankton: evolutionary and ecological archives in the sediment. Hydrobiologia 491:65-84

Caceres CE (1998) Interspecific variation in the abundance, production, and emergence of Daphnia diapausing eggs. Ecology 79:1699-1710

Carvalho GR, Wolf GH (1989) Resting eggs of lake-Daphnia I. Distribution, abundance and hatching of eggs collected from various depths in lake sediments. Freshw Biol 22:459-470

Childress JJ, Cowles DL, Favuzzi JA, Mickel TJ (1990) Metabolic rates of benthic deep-sea decapod crustaceans decline with increasing depth primarily due to the decline in temperature. Deep-Sea Res 37:929-949

Cousyn C, De Meester L (1998) The vertical profile of resting egg banks in natural populations of the pond-dwelling cladoceran Daphnia magna Straus. Arch Hydrobiol Spec Issues Advanc Limnol 52:127-139

Dahms H-U (1995) Dormancy in the Copepoda - an overview. Hydrobiologia 306:199-211

De Meester L, De Jager H (1993) Hatching of Daphnia sexual eggs. II. The effect of age and a second stimulus. Freshw Biol 30:227-233

Doma S (1978) Ephippia of Daphnia magna Strauss - a technique for their mass production and quick revival. Hydrobiologia 67:183-188

Hairston NG, Van Brunt RA, Kearns CM, Engstrom DR (1995) Age and survivorship of diapausing eggs in a sediment egg bank. Ecology 76:1706-1711

Hotovy J, Petrusek A (2007) Resting stage density and hatching of two cladoceran species from small ephemeral waters. Fundal Appl Limnol 169:177-187

Jańczak J (ed) (1999) Atlas of Polish Lakes-Tome III (in Polish). Bogucki Wydawnictwo Naukowe S.C, Poznań

Jones NT, Gilbert B (2016) Changing climate cues differentially alter zooplankton dormancy dynamics across latitudes. J Anim Ecol 85:559-569

Kerfoot WC, Weider LJ (2004) Experimental paleoecology (resurrection ecology): chasing Van Valen's Red Queen hypothesis. Limnol Oceanogr 49:1300-1316

Kozłowska A (2012) The synchronization of Daphnia magna males and ephippial females appearance in small astatic ponds of Warsaw (in Polish). Master's thesis, University of Warsaw, Warszawa
Lampert W (2011) Daphnia: development of a model organism in ecology and evolution. International Ecology Institute, Oldendorf/Luhe

Lukić D, Vad CF, Horváth Z (2016) Isolation by sugar flotation has no direct effect on the hatching success of zooplankton resting eggs. J Limnol 75:415-421

Moreira dos Santos MM, Persoone G (1998) Hatching of Daphnia magna resting eggs: the effect of storage duration and temperature. Arch Hydrobiol Spec Issues Advanc Limnol 52:253-262

Onbé T (1978) Sugar flotation method for sorting the resting eggs of marine cladocerans and copepods from sea-bottom sediment. Bull Japan Soc Sci Fish 44:1411

Pancella JR, Stross RG (1963) Light induced hatching of Daphnia resting eggs. Chesapeake Sci 4:135-140

Pfrender ME, Deng H-W (1998) Environmental and genetic control of diapause termination in Daphnia. Arch Hydrobiol Spec Issues Advanc Limnol 52:237-251

Pietrzak B, Ślusarczyk M (2006) The fate of ephippia-Daphnia dispersal in time and space. Pol J Ecol 54:709-714

Radzikowski J (2013) Resistance of dormant stages of planktonic invertebrates to adverse environmental conditions. J Plankton Res 35:707-723

Sars GO (1885) On some Australian Cladocera raised from dried mud. A.W. Broggers Bogtrykkeri, Christiania

Sars GO (1888) Additional notes on Australian Cladocera raised from dried mud. Jac. Dybwad, Christiania

Schultz TW (1977) Fine structure of the ephippium of Daphnia pulex (Crustacea: Cladocera). Trans Am Micros Soc 96:313-321

Schwartz SS, Hebert PDN (1987) Methods for the activation of the resting eggs of Daphnia. Freshw Biol 17:373-379

Seger J, Brockmann HJ (1987) What is bet-hedging? Oxf Surv Evol Biol 4:182-211

Ślusarczyk M (1998) Diapause as a survival strategy (in Polish). Wiad Ekol 44:279-303

Stross RG (1966) Light and temperature requirements for diapause development and release in Daphnia. Ecology 47:368-374

Surga K (2007) Production of resting eggs of Daphnia cucullata in the lakes of north-east Poland (in Polish). Master's thesis, University of Warsaw, Warszawa

Vandekerkhove J, Declerck S, Brendonck L, Conde-Porcuna JM, Jeppesen E, De Meester L (2005) Hatching of cladoceran resting eggs: temperature and photoperiod. Freshw Biol 50:96-104

Viitasalo M, Katajisto T (1994) Mesozooplankton resting eggs in the Baltic Sea: identification and vertical distribution in laminated and mixed sediments. Mar Biol 120:455-465

Weider LJ, Lampert W, Wessels M, Colbourne JK, Limburg P (1997) Long-term genetic shifts in a microcrustacean egg bank associated with anthropogenic changes in the Lake Constance ecosystem. Proc R Soc Lond B 264:1613-1618

Wood TR, Banta AM (1933) Observations on procuring and hatching sexual eggs of Daphnia longispina. Intern Revue Hydrobiol Hydrogr 29:437-454

Wood TR, Banta AM (1937) Hatchability of Daphnia and Moina sexual eggs without drying. Intern Revue Hydrobiol Hydrogr $35: 229-242$ 